\title{
Tingkat Pendidikan PUS Berhubungan dengan Pemilihan Jenis Alat Kontrasepsi tetapi Tidak Berhubungan dengan Keikutsertaan KB di Desa Argomulyo, Sedayu, Bantul, Yogyakarta
}

\author{
Beyna Handayani ${ }^{1}$, Nur Indah Rahmawati \\ 1,2 Universitas Alma Ata Yogyakarta \\ Jalan Ring Road Barat Daya No 1 Tamantirto, Kasihan, Bantul Yogyakarta \\ Email: beyna1211@gmail.com
}

\begin{abstract}
Abstrak
Data praktik komunitas pada tahun 2013 di Desa Argomulyo diketahui jumlah pasangan usia subur (PUS) adalah 900 pasangan dan yang mengikuti KB sejumlah 533 pasangan (59,22\%). Tujuan penelitian untuk mengetahui hubungan antara tingkat pendidikan PUS dengan keikutsertaan KB dan pemilihan jenis alat kontrasepsi pada PUS di Desa Argomulyo Sedayu Bantul Yogyakarta tahun 2014. Jenis penelitian observasional analitik dengan metode cross sectional. Populasinya adalah semua PUS di Dusun Puluhan, Kemusuk Kidul, Karang Lo, Pedes, Surobayan, Kali Berot di Desa Argomulyo, Sedayu Bantul, Yogyakarta sebanyak 916 pasangan. Sampel diambil menggunakan teknik total sampling dengan jumlah pasangan usia subur 907 pasangan dan 9 pasangan termasuk dalam kriteria eksklusi. Analisis data yang digunakan adalah chi-square. Hasil penelitian menunjukkan bahwa ada 610 pasangan (67,3\%) yang mengikuti KB dan 297 pasangan (32,7\%) tidak mengikuti KB. Hasil chi-square $\chi^{2}$ keikutsertaan KB istri 3,658 dan $x^{2}$ pemilihan jenis alat kontrasepsi istri 50,194, $x^{2}$ keikutsertaan KB suami 0,926 dan $\chi^{2}$ pemilihan jenis alat kontrasepsi suami 53,862. Kesimpulan tidak ada hubungan antara tingkat pendidikan pasangan usia subur dengan keikutsertaan KB dan ada hubungan antara tingkat pendidikan pasangan usia subur dengan pemilihan jenis alat kontrasepsi di Desa Argomulyo Sedayu Bantul Yogyakarta tahun 2014.
\end{abstract}

Kata Kunci: tingkat pendidikan, keikutsertaan KB, jenis alat kontrasepsi

\section{The Education Level of Reproductive Age Couples had Relationship with Selection of Contraceptives but Had No Relation with FP Participation in Argomulyo Village, Sedayu, Bantul, Yogyakarta}

\begin{abstract}
Based on data of community practices in 2013 at the Argomulyo village, total of reproductive age couples were 900 couples and 533 couples (59.22\%) following family planning (FP). The purpose of this study was to know the relationship between the education level of reproductive age couples with FP participation and selection of contraceptives on reproductive age couples in the Argomulyo village, Sedayu, Bantul Yogyakarta. The study design was observational analytic with the cross sectional. The total population of reproductive age couples in hamlet of Kemusuk Kidul, Karang lo, Pedes, Surobayan, Kali Berot in the Argomulyo village, Sedayu Bantul were 916 couples. Samples were selected by total sampling technique which consisted of 907 couples and 9 couples included in the exclusion criteria. Data analysis was done by chi-square test. The results showed that 610 couples (67.3\%) was following FP and 297 couples (32.7\%) not following FP programs. The results of chi-square $\chi^{2}$ of wife participation was 3.658 and selection of contraceptives was 50,194, $\chi^{2}$ of husband participation was 0.926 and selection of contraceptives was 53.862. In conclusion, there was no relationship between the education level of reproductive age couples with FP participation and there was a relationship between the education level of reproductive age couples with selection of contraceptives in Argomulyo village, Sedayu, Bantul, Yogyakarta.
\end{abstract}

Keywords: levels of education, FP participation, contraceptives selection

Info Artikel:

Artikel dikirim pada 19 April 2015

Artikel diterima pada 29 Mei 2015

DOI : http://dx.doi.org/10.21927/jnki.2016.4(1).11-18 


\section{PENDAHULUAN}

Perkembangan penduduk dunia saat ini terus mengalami peningkatan. Indonesia merupakan salah satu negara dengan jumlah penduduk terbanyak ke 4 di dunia. Pada tahun 2012 urutan pertama ditempati oleh China dengan jumlah penduduk 1.354,8 juta jiwa, peringkat ke dua diduduki oleh India dengan jumlah penduduk 1.261,0 juta jiwa, peringkat ke tiga diduduki oleh Amerika Serikat dengan jumlah penduduk 315,8 juta jiwa dan penduduk Indonesia menempati urutan ke empat dunia yaitu sebesar 244,2 juta jiwa(1).

Menurut Badan Kesejahteraan Keluarga Pemberdayaan Perempuan dan Keluarga Berencana (BKKPPKB) dan United Nations Population Found (UNFPA, 2005) pelaksanaan program KB masih mengalami beberapa hambatan sehingga jumlah kelahiran masih tinggi. Menurut Survei Demografi dan Kesehatan Indonesia (SDKI) 2012, masih sekitar 46\% Pasangan usia subur (PUS) yang belum menjadi akseptor KB. Tingkat prevalensi pemakaian alat kontrasepsi atau Contraceptive Prevalence Rate (CPR), yang menunjukkan tingkat kesertaan ber-KB di antara PUS mencapai 61,9\% (suatu cara). Sebanyak $57,9 \%$ di antaranya menggunakan cara KB modern, hanya meningkat sebesar $0,5 \%$ dari $57,4 \%$ dalam 5 tahun terakhir. Penggunaan kontrasepsi didominasi oleh alat kontrasepsi jangka pendek, terutama suntikan, yang mencapai $31,9 \%$. Tingkat pemakaian metode KB jangka panjang (MKJP), yaitu IUD, implan, metode operasi pria (MOP/vasektomi) target MDG's tahun 2015 adalah 4,5\% tetapi yang baru dicapai 0,27\% (2). Untuk metode operasi wanita (MOW/tubektomi) hanya sebesar 10,6\%. Kebutuhan ber-KB yang tidak terpenuhi (unmet need) sudah berhasil diturunkan menjadi $8,5 \%$ namun masih jauh dari sasaran yang telah ditetapkan(2).

Berdasarkan hasil survey BKKPPKB pada tahun 2013 di Provinsi Daerah Istimewa Yogyakarta, jumlah PUS sebanyak 1.104.844 jiwa dan yang menjadi peserta KB aktif sebanyak 877.576 jiwa. Sedangkan khusus untuk Kabupaten Bantul, Daerah Istimewa Yogyakarta, jumlah PUS sebanyak 152.793 peserta, pasangan yang menjadi peserta KB aktif pada tahun 2013 sebanyak 124.372 jiwa. Sementara pasangan usia subur yang bukan peserta keluarga berencana (KB) ada sebanyak 28.421(3). Dari data laporan pencapaian peserta KB dari 17 Kecamatan di Kabupaten Bantul untuk persentase pencapaian KB aktif di kecamatan Sedayu sebesar 83,46\%(4).

Dari hasil data praktik komunitas yang kemudian dijadikan sebagai data untuk studi pendahuluan pada 6 Dusun diketahui bahwa jumlah PUS pada tahun 2013 adalah 900 pasangan dan jumlah PUS yang mengikuti KB sejumlah 533 pasangan atau sekitar $59,22 \%$. Jika dilihat dari persentase berdasarkan data tersebut maka akseptor KB di 6 Dusun di Desa Argomulyo masih rendah. Keikutsertaan KB pada PUS di pengaruhi oleh beberapa faktor diantaranya adalah pengetahuan, pendidikan, agama, jumlah anak, sosial ekonomi dan dukungan pasangan atau dukungan keluarga akan mempengaruhi perkembangan dan kemajuan program KB di Indonesia. Dari hasil informasi setiap Kepala Dusun mengatakan bahwa tingkat pendidikan masyarakat di sana bervariasi. Dari beberapa penelitian yang pernah dilakukan, variabel latar belakang pendidikan responden merupakan variabel yang sejak lama dianggap memiliki pengaruh terhadap keikutsertaan KB. Menurut Westoff dan Bankole dalam Ubaidiyah penelitian yang dilakukan menunjukan bahwa variabel latar belakang pendidikan responden berpengaruh signifikan terhadap keikutsertaan $\mathrm{KB}(5)$.

Menurut Rizali et al. menuliskan bahwa semakin tinggi tingkat pendidikan akan jelas mempengaruhi pribadi seseorang berpendapat, berpikir, bersikap, lebih mandiri dan rasional dalam mengambil keputusan dan tindakan. Pendidikan juga akan meningkatkan kesadaran wanita terhadap manfaat yang dapat dinikmati bila ia mempunyai jumlah anak sedikit, sehingga akan mempengaruhi dalam mengambil keputusan dalam mengikuti program $\mathrm{KB}(6)$.

Tingkat pendidikan tidak saja mempengaruhi kerelaan menggunakan keluarga berencana tetapi juga pemilihan suatu metode. Beberapa studi telah memperlihatkan bahwa metode kalender lebih banyak digunakan oleh pasangan yang lebih berpendidikan. Dikatakan bahwa wanita yang berpendidikan biasanya menginginkan keluarga berencana yang efektif, tetapi tidak rela untuk mengambil resiko yang terkait dengan efek samping dari metode kontrasepsi(7). Tujuan penelitian untuk mengetahui hubungan antara tingkat pendidikan PUS dengan keikutsertaan KB dan pemilihan jenis alat kontrasepsi pada PUS di Desa Argomulyo Sedayu Bantul Yogyakarta tahun 2014.

\section{BAHAN DAN METODE}

Jenis penelitian ini adalah penelitian observasional analitik dengan menggunakan rancangan cross sectional. Populasi penelitian semua pasangan usia subur (PUS) yang sudah menikah di Dusun Puluhan, Kemusuk Kidul, karang Lo, Pedes, Surobayan, Kali Berot, Desa Argomulyo, Sedayu Bantul, Yogyakarta yaitu sebanyak 916 pasangan. Sampel diambil menggunakan teknik total sampling dengan jumlah pasangan usia subur 907 responden dan 9 responden termasuk dalam kriteria eksklusi. 
Tempat penelitian dilakukan di Desa Argomulyo, Sedayu, Bantul, Daerah Istimewa Yogyakarta, di Dusun Puluhan, Kemusuk Kidul, Karang Lo, Pedes, Surobayan dan Kali Berot. Penelitian ini dilakukan pada bulan Juni tahun 2014. Variabel independen dalam penelitian ini adalah tingkat pendidikan pasangan usia subur di enam Dusun di Desa Argomulyo, Sedayu, Bantul, Yogyakarta. Variabel dependen dalam penelitian ini adalah keikutsertaan KB pada pasangan usia subur dan pemilihan jenis KB pada pasangan usia subur di enam Dusun di Desa Argomulyo, Sedayu, Bantul, Yogyakarta. Instumen penelitian menggunakan kuesioner hasil adopsi penelitian sebelumnya(8). Analisis bivariat dalam penelitian ini dengan uji statistik chi-square.

\section{HASIL DAN BAHASAN}

\section{Karakteristik Responden}

Jumlah pasangan usia subur (PUS) yang mengikuti KB di Desa Argomulyo dalam 6 Dusun 610 dari 907 Pasangan Usia Subur yang menjadi responden. Hasil analisis data mengenai karakteristik responden dapat dilihat pada Tabel 1.

Tabel 1. Distribusi Frekuensi Karakteristik Responden Berdasarkan Umur Agama, Pendidikan di Desa Argomulyo Sedayu Bantul Yogyakarta

\begin{tabular}{lcccc}
\hline \multirow{2}{*}{ Karakteristik } & \multicolumn{2}{c}{ Istri } & \multicolumn{2}{c}{ Suami } \\
\cline { 2 - 5 } & $\mathbf{f}$ & $\%$ & $\mathbf{f}$ & $\%$ \\
\hline Umur & & & & \\
$\quad<20$ tahun & 4 & 0,4 & 1 & 0,1 \\
20- 35 tahun & 476 & 52,5 & 383 & 42,2 \\
$\quad>35$ tahun & 427 & 47,1 & 523 & 57,7 \\
Agama & & & & \\
$\quad$ Islam & 888 & 97,9 & 888 & 97,9 \\
$\quad$ Kristen & 10 & 1,1 & 10 & 1,1 \\
$\quad$ Budha & 0 & 0 & 0 & 0 \\
$\quad$ Hindu & 0 & 0 & 0 & 0 \\
$\quad$ Khatolik & 9 & 1,0 & 9 & 1,0 \\
$\quad$ Khonghucu & 0 & 0 & 0 & 0 \\
Pendidikan & & & & \\
$\quad$ Tidak tamat SD & 9 & 1,0 & 10 & 1,1 \\
$\quad$ SD/sederajat & 82 & 9,0 & 78 & 8,6 \\
$\quad$ SMP/sederajat & 150 & 16,5 & 127 & 14,0 \\
$\quad$ SMA/sederajat & 548 & 60,4 & 563 & 62,1 \\
$\quad$ Diploma/lebih tinggi & 118 & 13,0 & 129 & 14,2 \\
Jumlah & 907 & 100 & 907 & 100 \\
\hline
\end{tabular}

Sumber: Data Primer Tahun 2014

Berdasarkan Tabel 1 diketahui karakteristik umur responden istri sebagian besar berusia antara 20-35 tahun yaitu sebanyak $476(52,5 \%)$ responden dan responden suami sebagian berusia $>35$ tahun yaitu sebanyak $523(57,7 \%)$ responden. Untuk karakteristik agama sebagian besar beragama Islam yaitu sebanyak $888(97,9 \%)$ PUS. Untuk karakteristik pendidikan mayoritas pendidikan istri adalah SMA/ sederajat yaitu sebanyak $548(60,4 \%)$ dan pendidikan suami juga mayoritas adalah SMA/sederajat yaitu sebanyak $563(60,1 \%)$ responden.

\section{Keikutsertaan KB}

Hasil analisis data mengenai jumlah keikutsertaan KB di Desa Argomulyo, Sedayu, Bantul, Yogyakarta berdasarkan tingkat pendidikan istri dan suami disajikan dalam Tabel 2 dan Tabel 3.

Tabel 2. Distribusi Frekuensi Pendidikan Istri di Desa Argomulyo Sedayu Bantul Yogyakarta tahun 2014 dengan Keikutsertaan KB

\begin{tabular}{lcccc}
\hline \multicolumn{1}{c}{ Tingkat } & \multicolumn{4}{c}{ KB } \\
\cline { 2 - 5 } Pendidikan Istri & Ya & $\%$ & Tidak & $\%$ \\
\hline Tidak Tamat SD & 8 & 1,3 & 1 & 0,3 \\
SD & 54 & 8,9 & 28 & 9,4 \\
SMP & 107 & 17,5 & 43 & 14,5 \\
SMA & 365 & 59,8 & 183 & 61,6 \\
Diploma/PT & 76 & 12,5 & 42 & 14,1 \\
Jumlah & 610 & 100,0 & 297 & 100,0 \\
\hline
\end{tabular}

Sumber: Data Primer Tahun 2014

Tabel 3. Distribusi Frekuensi Pendidikan Suami di Desa Argomulyo Sedayu Bantul Yogyakarta tahun 2014 dengan Keikutsertaan KB

\begin{tabular}{lcccc}
\hline \multicolumn{1}{c}{ Tingkat } & \multicolumn{4}{c}{ KB } \\
\cline { 2 - 5 } Pendidikan Suami & Ya & $\%$ & Tidak & $\%$ \\
\hline Tidak Tamat SD & 7 & 1,1 & 3 & 1,0 \\
SD/sederajat & 52 & 8,5 & 26 & 8,8 \\
SMP/sederajat & 90 & 14,8 & 37 & 12,5 \\
SMA/sederajat & 375 & 61,5 & 188 & 63,3 \\
Diploma/PT & 86 & 14,1 & 43 & 14,5 \\
Jumlah & 610 & 100,0 & 297 & 100,0 \\
\hline
\end{tabular}

Sumber: Data Primer 2014

Berdasarkan Tabel 2 dan Tabel 3 menunjukkan sebagian besar PUS di Desa Argomulyo mengikuti KB yaitu sebanyak 610 responden $(67,3 \%)$ dan yang tidak ikut KB sebanyak 297 responden $(32,7 \%)$, dengan perincian tingkat pendidikan terbanyak yang mengikuti $\mathrm{KB}$ adalah dengan tingkat pendidikan menengah (tamat SMA/sederajat) responden istri sebanyak $365(59,8 \%)$ responden dan suami 375 $(61,5 \%)$ responden.

\section{Pemilihan Jenis Alat Kontrasepsi}

Hasil analisis data mengenai pemilihan jenis alat kontrasepsi dapat dilihat pada Tabel 4. 
Tabel 4. Distribusi Frekuensi Pendidikan Istri dengan Pemilihan Jenis Alat Kontrasepsi di Desa Argomulyo Sedayu Bantul Yogyakarta tahun 2014

\begin{tabular}{|c|c|c|c|c|c|c|c|c|c|c|c|c|}
\hline \multirow{3}{*}{ Jenis KB } & \multicolumn{10}{|c|}{ Tingkat Pendidikan Istri } & & \\
\hline & \multicolumn{2}{|c|}{$\begin{array}{c}\text { Tidak } \\
\text { Tamat SD }\end{array}$} & \multicolumn{2}{|c|}{$\begin{array}{c}\mathrm{SD} / \\
\text { sederajat }\end{array}$} & \multicolumn{2}{|c|}{$\begin{array}{c}\text { SMPI } \\
\text { Sederajat }\end{array}$} & \multicolumn{2}{|c|}{$\begin{array}{c}\text { SMA/ } \\
\text { sederajat }\end{array}$} & \multicolumn{2}{|c|}{$\begin{array}{c}\text { Diploma/ } \\
\text { PT }\end{array}$} & \multicolumn{2}{|c|}{ Jumlah } \\
\hline & $\mathbf{n}$ & $\%$ & $\mathbf{n}$ & $\%$ & $\mathbf{n}$ & $\%$ & $\mathbf{n}$ & $\%$ & $\mathbf{n}$ & $\%$ & $\mathbf{n}$ & $\%$ \\
\hline Tidak Memilih & 1 & 0,10 & 28 & 3,10 & 43 & 4,70 & 183 & 20,20 & 42 & 4,60 & 297 & 32,70 \\
\hline PIL & 1 & 0,10 & 7 & 0,80 & 17 & 1,90 & 60 & 6,60 & 7 & 0,80 & 92 & 10,10 \\
\hline IUD & 1 & 0,10 & 7 & 0,80 & 14 & 1,50 & 69 & 7,60 & 22 & 2,40 & 113 & 12,50 \\
\hline Suntik & 1 & 0,10 & 30 & 3,30 & 56 & 6,20 & 148 & 16,30 & 23 & 2,50 & 258 & 28,40 \\
\hline Implant & 1 & 0,10 & 0 & 0,00 & 4 & 0,40 & 15 & 1,70 & 4 & 0,40 & 24 & 2,60 \\
\hline Kondom & 2 & 0,20 & 2 & 0,20 & 8 & 0,90 & 33 & 3,60 & 12 & 1,30 & 57 & 6,30 \\
\hline Kontap & 1 & 0,10 & 5 & 0,60 & 4 & 0,40 & 14 & 1,50 & 1 & 0,10 & 25 & 2,80 \\
\hline Kalender & 1 & 0,10 & 2 & 0,20 & 2 & 0,20 & 19 & 2,10 & 7 & 0,80 & 31 & 3,40 \\
\hline Lain-Lain & 0 & 0,00 & 1 & 0,10 & 2 & 0,20 & 7 & 0,80 & 0 & 0,00 & 10 & 1,10 \\
\hline
\end{tabular}

Sumber: Data Primer Tahun 2014

Berdasarkan Tabel 4 menunjukkan bahwa distribusi frekuensi pemilihan jenis alat kontrasepsi berdasarkan tingkat pendidikan istri adalah sebagian besar memilih alat kontrasepsi jenis suntik yaitu sebanyak $258(28,4 \%)$ responden, sedangkan yang paling sedikit memilih alat kontrasepsi jenis lain-lain sebanyak $10(1,1 \%)$ responden. Untuk tingkat pendidikan Diploma/PT jenis alat kontrasepsi yang dipilih hampir sama antara IUD dan suntik, sedangkan yang memutuskan untuk tidak memilih jenis KB apapun lebih banyak yaitu $42(4,6 \%)$ responden.

Berdasarkan Tabel 5 menunjukan bahwa distribusi frekuensi pemilihan jenis alat kontrasepsi berdasarkan tingkat pendidikan suami adalah sebagian besar memilih alat kontrasepsi jenis suntik yaitu sebanyak $258(28,4 \%)$ responden, sedangkan yang paling sedikit memilih alat kontrasepsi jenis lain-lain sebanyak $10(1,1 \%)$ responden. Untuk tingkat pendidikan Diploma/PT jenis alat kontrasepsi yang dipilih sama antara IUD dan suntik yaitu 23 $(2,5 \%)$ responden, sedangkan yang memutuskan untuk tidak memilih jenis KB apapun lebih banyak yaitu $43(4,7 \%)$ responden.

\section{Hubungan antara Tingkat Pendidikan dengan keikutsertaan KB di Desa Argomulyo Sedayu Bantul Yogyakarta}

Tabulasi silang dan hasil uji statistik hubungan antara tingkat pendidikan dengan keikutsertaan KB di Desa Argomulyo Sedayu Bantul Yogyakarta disajikan pada Tabel 6.

Berdasarkan Tabel 6 menunjukkan bahwa responden istri dengan tingkat pendidikan tamat SMA/ sederajat lebih banyak mengikuti KB yaitu sebanyak $365(66,6 \%)$ responden sedangkan yang tidak ikut sebanyak $183(33,4 \%)$ responden. Keikutsertaan KB paling sedikit adalah responden dengan tingkat pendidikan tidak tamat SD yaitu $8(88,9 \%)$ responden dan yang tidak mengikuti KB $1(11,1 \%)$ responden.

Tabel 5. Distribusi Frekuensi Pendidikan Suami dengan Pemilihan Jenis Alat Kontrasepsi di Desa Argomulyo Sedayu Bantul Yogyakarta tahun 2014

\begin{tabular}{|c|c|c|c|c|c|c|c|c|c|c|c|c|}
\hline \multirow{3}{*}{ Jenis KB } & \multicolumn{10}{|c|}{ Tingkat Pendidikan Suami } & \multirow{2}{*}{\multicolumn{2}{|c|}{ Jumlah }} \\
\hline & \multicolumn{2}{|c|}{$\begin{array}{c}\text { Tidak } \\
\text { Tamat SD }\end{array}$} & \multicolumn{2}{|c|}{$\begin{array}{c}\text { SD/ } \\
\text { sederajat }\end{array}$} & \multicolumn{2}{|c|}{$\begin{array}{c}\text { SMPI } \\
\text { Sederajat }\end{array}$} & \multicolumn{2}{|c|}{$\begin{array}{c}\text { SMA/ } \\
\text { sederajat }\end{array}$} & \multicolumn{2}{|c|}{$\begin{array}{l}\text { Diploma/ } \\
\text { PT }\end{array}$} & & \\
\hline & $\mathbf{n}$ & $\%$ & $\mathbf{n}$ & $\%$ & $\mathbf{n}$ & $\%$ & $\mathbf{n}$ & $\%$ & $\mathbf{n}$ & $\%$ & $\mathbf{n}$ & $\%$ \\
\hline Tidak Memilih & 3 & 0,30 & 26 & 2,90 & 37 & 4,10 & 188 & 20,70 & 43 & 4,70 & 297 & 32,70 \\
\hline PIL & 1 & 0,10 & 6 & 0,70 & 19 & 2,10 & 58 & 6,40 & 8 & 0,90 & 92 & 10,10 \\
\hline IUD & 1 & 0,10 & 7 & 0,80 & 10 & 1,10 & 72 & 7,90 & 23 & 2,50 & 113 & 12,50 \\
\hline Suntik & 4 & 0,40 & 25 & 2,80 & 44 & 4,90 & 162 & 17,90 & 23 & 2,50 & 258 & 28,40 \\
\hline Implant & 0 & 0,00 & 2 & 0,20 & 2 & 0,20 & 16 & 1,80 & 4 & 0,40 & 24 & 2,60 \\
\hline Kondom & 1 & 0,10 & 1 & 0,10 & 9 & 1,00 & 30 & 3,30 & 16 & 1,80 & 57 & 6,30 \\
\hline Kontap & 0 & 0,00 & 7 & 0,80 & 2 & 0,20 & 15 & 1,70 & 1 & 0,10 & 25 & 2,80 \\
\hline Kalender & 0 & 0,00 & 3 & 0,30 & 2 & 0,20 & 17 & 1,90 & 9 & 1,00 & 31 & 3,40 \\
\hline Lain-Lain & 0 & 0,00 & 1 & 0,10 & 2 & 0,20 & 5 & 0,60 & 2 & 0,20 & 10 & 1,10 \\
\hline
\end{tabular}

Sumber: Data Primer Tahun 2014 
Hasil perhitungan uji statistik menggunakan chi-square seperti yang disajikan pada Tabel 6 bahwa hasil $\chi_{\text {hitung }}^{2}$ untuk hubungan antara tingkat pendidikan istri dengan keikutsertaan KB adalah 3,658 dan $p$-value $0,454>\alpha(0,05)$ sehingga dapat disimpulkan bahwa tidak ada hubungan yang signifikan antar tingkat pendidikan istri dengan keikutsertaan KB.

Berdasarkan Tabel 7 menunjukkan bahwa responden suami dengan tingkat pendidikan tamat SMA/sederajat lebih banyak mengikuti KB yaitu sebanyak $375(66,6 \%)$ responden sedangkan yang tidak ikut sebanyak $183(33,4 \%)$ responden. Keikutsertaan KB paling sedikit adalah responden dengan tingkat pendidikan tidak tamat SD yaitu $7(70 \%)$ responden dan yang tidak mengikuti KB $3(30 \%)$ responden.

Hasil perhitungan uji statistik menggunakan chi-square seperti yang disajikan pada Tabel 7 bahwa hasil $\chi_{\text {hitung }}^{2}$ untuk hubungan antara tingkat pendidikan suami dengan keikutsertaan KB adalah 0,926 dan $p$-value $0,921>\alpha(0,05)$ sehingga dapat disimpulkan bahwa tidak ada hubungan yang signifikan antar tingkat pendidikan suami dengan keikutsertaan KB.

Berdasarkan Tabel 6 dan Tabel 7, baik tingkat pendidikan istri maupun suami sama-sama tidak memiliki hubungan yang signifikan dengan keikutsertaan KB. Hasil penelitian ini didukung dengan penelitian Ubaidiyah bahwa tidak ada hubungan yang signifikan antara tingkat pendidikan dengan keikutsertaan $\mathrm{KB}(5)$. Sejalan dengan penelitian Maharyani yang mengatakan bahwa tidak ada hubungan yang signifikan antara pendidikan dengan keikutsertaan suami menjadi akseptor KB di Wilayah Desa Karangduwur Kecamatan Petanahan Kabupaten Kebumen Jawa Tengah(9).

Berdasarkan pendapat Kartini, bahwa bukan berarti seseorang yang berpendidikan rendah maka akan memiliki pengetahuan yang rendah pula, karena peningkatan pengetahuan seseorang tidak hanya diperoleh dari pendidikan formal saja, akan tetapi diperoleh melalui pendidikan non formal, sehingga bisa saja seseorang dengan pendidikan rendah ataupun tinggi memutuskan sesuatu berdasarkan pengetahuan dan pengalaman(10).

Penelitian ini tidak sejalan dengan penelitian Saputra yang mengatakan bahwa ada hubungan yang signifikan antara pendidikan suami dengan partisipasi suami menjadi akseptor KB(11). Serta pendapat Rahmanti yang menyatakan bahwa ada hubungan antara tingkat pendidikan dan keikutsertaan melaksanakan program KB pada ibu nifas yang mengikuti Jampersal di Kecamatan Kemiri Kabupaten Purworejo Jawa Tengah(12).

Tabel 6. Hubungan antara Tingkat Pendidikan Istri dengan Keikutsertaan KB dalam 6 Dusun di Desa Argomulyo Sedayu Bantul Yogyakarta

\begin{tabular}{|c|c|c|c|c|c|c|c|c|}
\hline \multirow{3}{*}{$\begin{array}{c}\text { Tingkat } \\
\text { Pendidikan }\end{array}$} & \multicolumn{4}{|c|}{ Keikutsertaan KB } & \multirow{2}{*}{\multicolumn{2}{|c|}{ Total }} & \multirow{3}{*}{$\chi^{2}$ hitung } & \multirow{3}{*}{ p-value } \\
\hline & \multicolumn{2}{|c|}{ Ya } & \multicolumn{2}{|c|}{ Tidak } & & & & \\
\hline & $\mathbf{n}$ & $\%$ & $\mathbf{n}$ & $\%$ & $\mathbf{n}$ & $\%$ & & \\
\hline Tidak Tamat SD & 8 & 88,9 & 1 & 11,1 & 9 & 100 & 3,658 & 0,454 \\
\hline SD/sederajat & 54 & 65,9 & 28 & 34,1 & 82 & 100 & & \\
\hline SMP/sederajat & 107 & 71,3 & 43 & 28,7 & 150 & 100 & & \\
\hline SMA/sederajat & 365 & 66,6 & 183 & 33,4 & 548 & 100 & & \\
\hline Diploma/PT & 76 & 64,4 & 42 & 35,6 & 118 & 100 & & \\
\hline Jumlah & 610 & 67,3 & 297 & 32,7 & 907 & 100 & & \\
\hline
\end{tabular}

Sumber: Data Primer Tahun 2014

Tabel 7. Hubungan antara Tingkat Pendidikan Suami dengan Keikutsertaan KB dalam 6 Dusun di Desa Argomulyo Sedayu Bantul Yogyakarta

\begin{tabular}{|c|c|c|c|c|c|c|c|c|}
\hline \multirow{3}{*}{ Tingkat Pendidikan } & \multicolumn{4}{|c|}{ Keikutsertaan KB } & \multirow{2}{*}{\multicolumn{2}{|c|}{ Total }} & \multirow{3}{*}{$\chi^{2}$ hitung } & \multirow{3}{*}{ p-value } \\
\hline & \multicolumn{2}{|c|}{ Ya } & \multicolumn{2}{|c|}{ Tidak } & & & & \\
\hline & $\mathbf{n}$ & $\%$ & $\mathbf{n}$ & $\%$ & $\mathbf{n}$ & $\%$ & & \\
\hline Tidak Tamat SD & 7 & 70 & 3 & 30 & 10 & 100 & 0,926 & 0,921 \\
\hline SD/sederajat & 52 & 66,7 & 26 & 33,3 & 78 & 100 & & \\
\hline SMP/sederajat & 90 & 70,9 & 37 & 29,1 & 127 & 100 & & \\
\hline SMA/sederajat & 375 & 66,6 & 188 & 33,4 & 563 & 100 & & \\
\hline Diploma/PT & 86 & 66,7 & 43 & 33,3 & 129 & 100 & & \\
\hline Jumlah & 610 & 67,3 & 297 & 32,7 & 907 & 100 & & \\
\hline
\end{tabular}

Sumber: Data Primer Tahun 2014 
Hubungan Tingkat Pendidikan dengan pemilihan jenis alat kontrasepsi di Desa Argomulyo Sedayu Bantul Yogyakarta

Hasil Tabulasi silang antara tingkat pendidikan suami dan istri dengan pemilihan jenis alat kontrasepsi disajikan dalam Tabel 8 dan Tabel 9.

Berdasarkan Tabel 8 menunjukan bahwa responden istri dengan tingkat pendidikan tamat SMA/sederajat lebih banyak yang mengikuti KB dan lebih memilih alat kontrasepsi suntik yaitu sebanyak $148(57,4 \%)$ responden. Alat kontrasepsi jenis suntik dari semua tingkat pendidikan diikuti sebanyak 258 responden, pada tingkat pendidikan tidak tamat SD tidak tampak perbedaan yang besar dalam pemilihan jenis alat kontrasepsi, pemilihan alat kontrasepsi jenis suntik tampak dominan dimulai dari tingkat pendidikan SD, SMP, SMA sedangkan untuk tingkat pendidikan Diloma/PT tidak jauh berbeda antara IUD dan suntik.

Hasil perhitungan uji statistik menggunakan chisquare seperti yang disajikan pada Tabel 8 bahwa hasil $\chi_{\text {hitung }}^{2}$ untuk hubungan antara tingkat pendidikan istri dengan pemilihan jenis alat kontrasepsi adalah 50,194 dan $p$-value $0,021<\alpha(0,05)$ sehingga dapat disimpulkan bahwa ada hubungan yang signifikan antara tingkat pendidikan istri dengan pemilihan jenis alat kontrasepsi.

Berdasarkan Tabel 9 menunjukkan bahwa responden suami dengan tingkat pendidikan tamat SMA/sederajat lebih banyak yang mengikuti KB dan lebih memilih alat kontrasepsi suntik yaitu sebanyak

Tabel 8. Hubungan antara Tingkat Pendidikan Istri dengan Pemilihan Jenis Alat Kontrasepsi dalam 6 Dusun di Desa Argomulyo Sedayu Bantul Yogyakarta

\begin{tabular}{|c|c|c|c|c|c|c|c|c|c|c|c|c|c|c|}
\hline \multirow{3}{*}{ Jenis KB } & \multicolumn{10}{|c|}{ Tingkat Pendidikan Istri } & & & \multirow{3}{*}{$\chi^{2}$ hitung } & \multirow{3}{*}{ p-value } \\
\hline & \multicolumn{2}{|c|}{$\begin{array}{c}\text { Tidak } \\
\text { Tamat } \\
\text { SD }\end{array}$} & \multicolumn{2}{|c|}{$\begin{array}{c}\text { SD/ } \\
\text { sederajat } \\
\end{array}$} & \multicolumn{2}{|c|}{$\begin{array}{c}\text { SMPI } \\
\text { Sederajat }\end{array}$} & \multicolumn{2}{|c|}{$\begin{array}{c}\text { SMA/ } \\
\text { Sederajat }\end{array}$} & \multicolumn{2}{|c|}{$\begin{array}{c}\text { Diploma/ } \\
\text { PT } \\
\end{array}$} & \multicolumn{2}{|c|}{ Total } & & \\
\hline & $\mathbf{n}$ & $\%$ & $\mathbf{n}$ & $\%$ & $\mathbf{n}$ & $\%$ & $\mathbf{n}$ & $\%$ & $\mathbf{n}$ & $\%$ & $\mathbf{n}$ & $\%$ & & \\
\hline Tidak Memilih & 1 & 0,3 & 28 & 9,4 & 43 & 14,5 & 183 & 61,7 & 42 & 14,1 & 297 & 100 & 50,194 & 0,021 \\
\hline PIL & 1 & 1,1 & 7 & 7,6 & 17 & 18,5 & 60 & 65,2 & 7 & 7,6 & 92 & 100 & & \\
\hline IUD & 1 & 0,9 & 7 & 6,2 & 14 & 12,4 & 69 & 61,1 & 22 & 19,5 & 113 & 100 & & \\
\hline Suntik & 1 & 0,4 & 30 & 11,6 & 56 & 21,7 & 148 & 57,4 & 23 & 8,9 & 258 & 100 & & \\
\hline Implant & 1 & 4,2 & 0 & 0 & 4 & 16,7 & 15 & 62,5 & 4 & 16,7 & 24 & 100 & & \\
\hline Kondom & 2 & 3,5 & 2 & 3,5 & 8 & 14 & 33 & 57,9 & 12 & 21,1 & 57 & 100 & & \\
\hline Kontap & 1 & 4 & 5 & 20 & 4 & 16 & 14 & 56 & 1 & 4 & 25 & 100 & & \\
\hline Kalender & 1 & 3,2 & 2 & 6,5 & 2 & 6,5 & 19 & 61,3 & 7 & 22,6 & 31 & 100 & & \\
\hline MAL & 0 & 0 & 0 & 0 & 1 & 16,7 & 5 & 83,3 & 0 & 0 & 6 & 100 & & \\
\hline S.Terputus & 0 & 0 & 1 & 25 & 1 & 25 & 2 & 50 & 0 & 0 & 4 & 100 & & \\
\hline Jumlah & 9 & 1 & 82 & 9 & 150 & 16,5 & 548 & 60,4 & 118 & 13 & 907 & 100 & & \\
\hline
\end{tabular}

Sumber: Data Primer Tahun 2014

Tabel 9. Hubungan antara Tingkat Pendidikan Suami dengan Pemilihan Jenis Alat Kontrasepsi dalam 6 Dusun di Desa Argomulyo Sedayu Bantul Yogyakarta

\begin{tabular}{|c|c|c|c|c|c|c|c|c|c|c|c|c|c|c|}
\hline \multirow{3}{*}{ Jenis KB } & \multicolumn{10}{|c|}{ Tingkat Pendidikan Suami } & & & \multirow{3}{*}{$\chi^{2}$ hitung } & \multirow{3}{*}{$p$-value } \\
\hline & \multicolumn{2}{|c|}{$\begin{array}{c}\text { Tidak } \\
\text { Tamat SD }\end{array}$} & \multicolumn{2}{|c|}{$\begin{array}{c}\mathrm{SD} / \\
\text { sederajat }\end{array}$} & \multicolumn{2}{|c|}{$\begin{array}{c}\text { SMPI } \\
\text { Sederajat }\end{array}$} & \multicolumn{2}{|c|}{$\begin{array}{c}\text { SMA } \\
\text { Sederajat }\end{array}$} & \multicolumn{2}{|c|}{$\begin{array}{c}\text { Diplomal } \\
\text { PT }\end{array}$} & \multicolumn{2}{|c|}{ Total } & & \\
\hline & $\mathrm{n}$ & $\%$ & $\mathbf{n}$ & $\%$ & $\mathbf{n}$ & $\%$ & $\mathbf{n}$ & $\%$ & $\mathbf{n}$ & $\%$ & $\mathbf{n}$ & $\%$ & & \\
\hline T.Memilih & 3 & 1 & 26 & 8,8 & 37 & 12,5 & 188 & 63,3 & 43 & 14,5 & 297 & 100 & 53,862 & 0,009 \\
\hline PIL & 1 & 1,1 & 6 & 6,5 & 19 & 20,7 & 58 & 63 & 8 & 8,7 & 92 & 100 & & \\
\hline IUD & 1 & 0,9 & 7 & 6,2 & 10 & 8,8 & 72 & 63,7 & 23 & 20,4 & 113 & 100 & & \\
\hline Suntik & 4 & 1,6 & 25 & 9,7 & 44 & 17,1 & 162 & 62,8 & 23 & 8,9 & 258 & 100 & & \\
\hline Implant & 0 & 0 & 2 & 8,3 & 2 & 8,3 & 16 & 66,7 & 4 & 16,7 & 24 & 100 & & \\
\hline Kondom & 1 & 1,8 & 1 & 1,8 & 9 & 15,8 & 30 & 52,6 & 16 & 28,1 & 57 & 100 & & \\
\hline Kontap & 0 & 0 & 7 & 28 & 2 & 8 & 15 & 60 & 1 & 4 & 25 & 100 & & \\
\hline Kalender & 0 & 0 & 3 & 9,7 & 2 & 6,5 & 17 & 54,8 & 9 & 29 & 31 & 100 & & \\
\hline MAL & 0 & 0 & 1 & 25 & 1 & 16,7 & 4 & 66,7 & 0 & 0 & 6 & 100 & & \\
\hline S.Terputus & 0 & 0 & 0 & 0 & 1 & 25 & 1 & 25 & 2 & 50 & 4 & 100 & & \\
\hline Jumlah & 10 & 1,1 & 78 & 8,6 & 127 & 14,0 & 563 & 62,1 & 129 & 14,2 & 907 & 100 & & \\
\hline
\end{tabular}

Sumber: Data Primer Tahun 2014 
$162(62,8 \%)$ responden. Alat kontrasepsi jenis suntik dari semua tingkat pendidikan diikuti sebanyak 258 responden, pada tingkat pendidikan tidak tamat SD tidak tampak sedikit perbedaan dalam pemilihan jenis alat kontrasepsi, pemilihan alat kontrasepsi jenis suntik tampak dominan dimulai dari tingkat pendidikan SD, SMP, SMA sedangkan untuk tingkat pendidikan Diloma/PT tidak ada perbedaan antara jumlah yang memilih IUD dan suntik yaitu sebanyak 23 responden.

Hasil perhitungan uji statistik menggunakan chisquare seperti yang disajikan pada Tabel 9 bahwa hasil $\chi_{\text {hitung }}^{2}$ untuk hubungan antara tingkat pendidikan suami dengan pemilihan jenis alat kontrasepsi adalah 53,862 dan $p$-value $0,009<\alpha(0,05)$ sehingga dapat disimpulkan bahwa ada hubungan yang signifikan antar tingkat pendidikan istri dengan pemilihan jenis alat kontrasepsi.

Berdasarkan Tabel 8 dan Tabel 9, baik tingkat pendidikan istri maupun suami sama-sama memiliki hubungan yang signifikan dengan pemilihan jenis alat kontrasepsi. Penelitian ini sejalan dengan hasil penelitian Ismail dan Febryani yang menyatakan bahwa ada hubungan antara tingkat pendidikan PUS dengan pemilihan alat kontrasepsi mantap di Desa Karangampel Kidul Kecamatan Karangampel Kabupaten Indramayu(13). Didukung juga oleh hasil penelitian Kusumaningrum yang menyatakan bahwa tingkat pendidikan memiliki hubungan yang bermakna dengan pemilihan jenis kontrasepsi yang digunakan pada PUS(14). Serta pendapat Lontaan yang menyatakan bahwa ada hubungan antara pendidikan dengan pemilihan kontrasepsi(15).

Penelitian ini tidak sejalan dengan penelitian Grestasari yang menyatakan tidak ada hubungan antara tingkat pendidikan dengan pemilihan jenis kontrasepsi(16). Adyani juga menyatakan hal yang sama bahwa faktor tingkat pendidikan tidak memiliki hubungan yang signifikan dengan pemilihan jenis kontrasepsi pada akseptor wanita usia 20-39 tahun(17).

\section{SIMPULAN DAN SARAN}

Berdasarkan hasil analisis yang telah dilakukan dapat ditarik kesimpulan tingkat pendidikan responden di Desa Argomulyo Sedayu Bantul Yogyakarta, khususnya di Dusun Puluhan, Kemusuk Kidul, Karang Lo, Pedes, Surobayan dan Kaliberot mayoritas lulusan SMA/sederajat, keikutsertaan KB 67,3\% ikut KB, pemilihan jenis alat kontrasepsi terbanyak adalah suntik, tidak ada hubungan antara tingkat pendidikan pasangan usia subur dengan keikutsertaan KB, dan ada hubungan antara tingkat pendidikan pasangan usia subur dengan pemilihan jenis alat kontrasepsi di Desa Argomulyo Sedayu Bantul Yogyakarta tahun 2014.
Selama waktu penelitian bagi PUS di Desa Argomulyo Sedayu Batul Yogyakarta tahun 2014 dapat digunakan untuk membantu dalam pemilihan alat kontrasepsi yang efektif. Sebagai referensi dalam penyusunan program, khususnya pada pelayanan KB bagi tenaga kesehatan agar lebih memperhatikan kualitas pelayanan program yang baik dan dapat meningkatkan keikutsertaan KB pada pasangan usia subur serta lebih meningkatkan dan mengembangkan program sosialisasi tentang efek samping berbagai macam jenis alat kontrasepsi. Sumbangan aplikatif bagi tenaga kesehatan khususnya bidan, sehingga profesi Bidan khususnya dapat memberikan perhatian khusus dalam membuat program khusus untuk mempromosikan tentang berbagai macam jenis alat kontrasepsi pada PUS dengan berbagai tingkatan pendidikan agar dapat meningkatkan cakupan KB. Sebagai bahan informasi yang meningkatkan kinerja lintas program terkait dengan KB, guna membantu keberhasilan program KB wilayah setempat serta mengembangkan sikap positif terhadap info tentang $\mathrm{KB}$, serta bagi perangkat desa dapat bekerja sama dengan petugas kesehatan untuk lebih meningkatkan sosialisasi tentang KB dan macammacam jenis alat kontrasepsi.

\section{RUJUKAN}

1. BPS. Perkiraan Penduduk Beberapa Negara 2008-2012. Yogyakarta: Badan Pusat Statistik; 2013.

2. BKKPPKB. Siaran pers BkkbN. Jakarta: BKKPPKB; 2013.

3. BKKPPKB. Data Laporan Bulanan, Kantor KB Yogyakarta. DIY: BKKPPKB; 2013.

4. BKKPPKB. Data Hasil Kegiatan Program KB Nasional Kabupaten Bantul. Bantul: BKKPPKB; 2013.

5. Ubaidiyah. Hubungan antara umur, pendidikan, jumlah anak masih hidup dengan kejadian unmet need KB pada pasangan usia subur (PUS) di Kota Yogyakarta. STIKES Alma Ata Yogyakarta; 2013.

6. Rizali, Ikhsan, Ummu. Faktor yang berhubungan dengan pemilihan metode kontrasepsi suntik di kelurahan Mattoangin kecamatan Mariso kota Makasar tahun 2013. Universitas Hasanuddin Makassar; 2013.

7. Handayani S. Buku ajar Pelayanan Keluarga Berencana. Yogyakarta: Pustaka Rihama; 2010.

8. Hadi H. Faktor-Faktor yang Berhubungan dengan terjadinya Unmet Need KB pada PUS di Kota Yogyakarta Tahun 2013. Yogyakarta; 2013. 
9. Maharyani HW, Handayani S. Hubungan Karakteristik Suami Dengan Keikutsertaan Suami Menjadi Akseptor Keluarga Berencana Di Wilayah Desa Karangduwur Kecamatan Petanahan Kabupaten Kebumen Jawa Tengah. J Kesehat Masy UAD [Internet]. 2010;4(1):49-58. Available from: http://journal.uad.ac.id/index.php/KesMas/ article/view/1102

10. Kartini LI. Faktor-faktor yang mempengaruhi pemilihan jenis kontrasepsi yang digunakan pada keluarga miskin. Universitas Diponegoro; 2009.

11. Saputra AM. Hubungan antara Pengetahuan, Pendidikan dan Persepsi Suami Tentang Keluarga Berencana dengan Partisipasi Suami Menjadi Akseptor Keluarga Berencana di Indonesia. J Poltekkes Palembang [Internet]. 2014;1(13):1-14. Available from: http://jurnal.poltekkespalembang. ac.id/wp-content/uploads/2015/11/2.pdf

12. Rahmanti R. Hubungan antara Tingkat Pendidikan dan Keikutsertaan Melaksakan Program KB pada Ibu Nifas yang Mengikuti Jampersal di Kecamatan Kemiri Kabupaten Purworejo Jawa Tengah. Universita Muhammadiyah Surakarta; 2014.

13. Ismail, Febryani S. Hubungan Tingkat Pendidikan dan Pengetahuan Pasangan Usia Subur (PUS)
Terhadap Pemilihan Alat Kontrasepsi Mantap (Kontap) Di Desa Karangampel Kidul Kabupaten Indramayu. J Gema Wiralodra [Internet]. 2012;6(8):1-7. Available from: http://ejournal. unwir.ac.id/file.php?file=preview jurnal\&id $=563$ $\& c d=0 b 2173 f f 6 a d 6 a 6 f b 09 c 95 f 6 d 50001 d f 6 \& n a m$ e=ismail_no8.pdf

14. Kusumaningrum R. Faktor-Faktor yang Mempengaruhi Pemilihan Jenis Kontrasepsi yang digunakan pada Pasangan Usia Subur. Universitas Diponegoro; 2009.

15. Lontaan A, Kusmiyati, Dompas R. Faktor-Faktor yang Berhubungan dengan Pemilihan Kontrasepsi Pasangan Usia Subur di Puskesmas Damau Kabupaten Talaud. J IIm Bidan. 2014;2(1):1-6.

16. Grestasari LE. Hubungan antara Tingkat Pendidikan, Pengetahuan, dan Usia Ibu Pus dengan Pemilihan Jenis Kontrasepsi di Desa Jetak Kecamatan Sidoharjo Kabupaten Sragen. Universitas Muhammadiyah Surakarta; 2014.

17. Adhyani AR. Faktor-Faktor yang Berhubungan dengan Pemilihan Kontrasepsi Non IUD pada Akseptor KB Wanita Usia 20-39 Tahun. Universitas Diponegoro; 2012. 